\title{
OS PERCALÇOS DO SINDICALISMO E SUA RESSIGNIFICAÇÃO NO ESTADO DEMOCRÁTICO DE DIREITO
}

\author{
Bruno Ferraz Hazan* \\ Luciana Costa Poli*
}

RESUMO: O trabalho tem como objetivo inicial demonstrar os caminhos percorridos pelos sindicatos, desde o Estado Liberal - com a formação do Direito do Trabalho -, até o Estado Social - na fase de consolidação do ramo trabalhista. Em sequência, investigar-se-á a consagração da liberdade sindical como direito humano e sua relação com os parâmetros democráticos e pluralistas do Estado Democrático de Direito. Essa correlação permitiria, ao inserir os trabalhadores - e suas organizações sindicais - nos centros de poder, não apenas efetivar o princípio, mas repensar o papel dos sindicatos, agora que fundamentalizados e atrelados aos próprios paradigmas do Estado.

Palavras-Chave: Sindicato; Sindicalismo; Liberdade sindical; Estado Democrático de Direito.

\section{THE ADVERSITIES OF SYNDICALISM AND ITS RESSIGNIFICATION IN THE DEMOCRATIC STATE OF LAW}

\begin{abstract}
The work intends, as initial objective, to demonstrate the paths taken by unions, from the Liberal State - formation of Labor Law - to the Welfare State consolidation of the labor branch. In a sequel, it will investigate the consecration of freedom of association as a human right and its relation to the democratic and pluralist parameters of the Democratic State of Law. This correlation would allow, by inserting the workers - and their unions - into the centers of power, not only to implement the principle, but to rethink the role of the unions, now that they are grounded to the State's paradigms.
\end{abstract}

Keywords: Trade Union; Syndicalism; Freedom of association; Democratic State of Law.

\section{INTRODUÇÃO}

A edificação de um Direito do Trabalho efetivo e eficaz permite a consolidação e a afirmação de uma sociedade verdadeiramente democrática. Os sindicatos, por sua vez, representam um importante instrumento de desenvolvimento do Direito do Trabalho, seja por meio das lutas por melhores condições de trabalho e vida, seja pelo elo de identidade que firmam entre o sujeito trabalhador e sua classe. Além disso, a postura do Estado capitalista -

\footnotetext{
* Bruno Ferraz Hazan. Doutor em Direito Privado e Mestre em Direito do Trabalho pela Pontifícia Universidade Católica de Minas Gerais. Professor na Escola Superior Dom Helder Câmara/MG.

* Luciana Costa Poli. Pós-Doutora pela UNESP (Bolsista da CAPES/PNPD). Doutora em Direito Privado pela Pontifícia Universidade Católica de Minas Gerais. Mestra em Direito e Instituições Políticas pela Universidade FUMEC/MG. Professora na Pontifícia Universidade Católica de Minas Gerais/MG.
} 
compelido a aceitar como legais e legítimas as organizações sindicais - sempre esteve vinculada à capacidade de mobilização dos trabalhadores.

A fundamentalidade do sindicalismo para a implementação e para o aperfeiçoamento da democracia pode ser percebida, também, a partir da consagração da liberdade sindical como direito humano e fundamental. Não sem razão, as principais Constituições contemporâneas incorporaram, em seu arcabouço normativo, os direitos trabalhistas e princípios sindicais a fim de efetivá-los.

Com base nessas premissas, o presente trabalho pretende investigar os percalços do sindicalismo na conformação do Direito do Trabalho, incluindo o seu papel central na mudança dos próprios paradigmas estatais. Essa atuação direta demonstra que a intervenção do Estado na legalização das condições de trabalho não afastou a premissa plural intrínseca do ramo trabalhista que, decerto, foi construído autonomamente pela classe trabalhadora.

Assim, a estrutura democrática e pluralista do Estado Democrático de Direito não apenas se torna compatível com o exercício autônomo do poder criativo dos trabalhadores, mas permite a inserção de toda a classe trabalhadora - por meio de suas organizações sindicais - nos centros de poder.

Seria possível, a partir disso, compreender que a liberdade sindical, na verdade, transmutou-se em corolário do próprio paradigma do Estado. Ao final, pretende-se constatar que o reconhecimento dessa liberdade como direito humano torna patente a fundamentalidade do sindicalismo para a implementação e aperfeiçoamento da democracia. Em última análise, a releitura constitucional propiciada pelo Estado Democrático de Direito viabilizaria não só a consolidação do sindicalismo com ênfase em sua centralidade, mas o desenvolvimento de seu papel fundante e sua ressignificação para o Direito do Trabalho.

\section{DO SINDICALISMO ESPONTÂNEO À LEGALIZAÇÃO DA CLASSE TRABALHADORA}

O trabalho, sob uma ótica objetiva, pode ser apreendido como resultado da força criativa do ser humano (RENAULT, 2004, p. 45). Apesar de constituir toda e qualquer ordem produtiva, já que traduz basicamente o domínio da natureza pelo homem, o trabalho só adquiriu contornos que lhe cominaram repercussões jurídicas quando o capitalismo se consolidou como modo de produção: 
Somente com a hegemonia burguesa e a consolidação do sistema de metabolismo social do capital que a força de trabalho passa a ser mercantilizada, enquanto objeto de contrato, passando a ser peça fundante no processo de valorização. Marx é, nesse sentido, taxativo, ao afirmar que "um dos pressupostos do trabalho assalariado e uma das condições históricas do capital é o trabalho livre e a troca do trabalho livre por dinheiro". (MACHADO, 2016, p. 95)

Nessa perspectiva, a própria consciência de classe, decorrente consciência coletiva dos trabalhadores na luta contra as mazelas provenientes do trabalho nas indústrias, pode ser encarada como um fenômeno da era industrial moderna:

[...] No capitalismo a classe é uma realidade histórica imediata e em certo sentido vivenciada diretamente, enquanto nas épocas pré-capitalistas ela pode ser meramente um conceito analítico que dá sentido a um complexo de fatos que de outro modo seriam inexplicáveis. (HOBSBAWM, 2000, p. 36-37)

De início, tem-se que o fim do trabalho servil e do trabalho escravo e o surgimento do trabalho livre criaram condições para a estruturação de normas reguladoras e controladoras da relação entre tomadores de serviço e trabalhadores. Afirma-se, assim, que o Direito do Trabalho, com sua lógica tuitiva e com a formatação que assumiu enquanto ramo jurídico especializado, é fruto e parte integrante do sistema capitalista - o que oportuniza a redução das distorções econômicas e sociais inerentes ao sistema que integra (DELGADO, 2016, p. 87).

É importante registrar que não foi o trabalho livre por si o propulsor da idealização e da construção do Direito do Trabalho. Na verdade, a proteção daqueles que vendiam sua força de trabalho ao capital se tornou reivindicação coletiva diante da superexploração praticada nas fábricas, superexploração esta fomentada pelo pensamento liberal.

O liberalismo ganhou espaço no fim do século XVIII e início do século XIX, a partir da Revolução Francesa. De acordo com Hunt e Sherman (1986, p. 69), “a análise de Adam Smith sobre o mercado, concebido como a 'mão invisível' que canalizava as motivações egoístas dos homens para atividades de maior utilidade social, proporcionou os fundamentos da doutrina do laissez-faire".

Como teoria econômica, o liberalismo defende a economia de mercado; como teoria política, defende o que hoje se chama de Estado-Mínimo (BOBBIO, 2002, p. 128). Dentre seus postulados básicos, destacam-se: a eliminação da moral como essência da coesão social; a contratualização da responsabilidade, com exclusão da fraternidade (que não se define em 
termos obrigacionais) e da obrigação da sociedade para com seus membros; a legitimação da desigualdade (e igualdade), vinculando-a ao mercado; e a igualdade como pressuposto das relações intersubjetivas, sendo dever do Estado impedir obstáculos à liberdade (EWALD, 1996, p. 26).

As políticas públicas adotadas pelo Estado Liberal serviam basicamente à viabilização do exercício dos chamados direitos fundamentais de primeira geração ou dimensão, quais sejam, os civis e os políticos. Sarlet (2009, p. 46-47) explica que tais direitos, que tiveram sua jusfundamentalidade reconhecida sob o manto do liberalismo, asseguravam a vida, a liberdade, a propriedade privada e a igualdade perante a lei e se apresentavam como direitos de defesa, que demarcavam uma zona de não-intervenção do Estado e uma esfera de autonomia individual em face do poder estatal.

A aparente distância que o Estado mantinha das relações privadas e sua posição omissa quanto à regulação da economia implicavam a sujeição dos trabalhadores às determinações dos patrões ${ }^{1}$. Não é difícil perceber que o absenteísmo econômico estatal típico do paradigma liberal era proposital e constituía terreno fértil para a superexploração da mão de obra e para a exclusão social, já que as relações laborais eram conduzidas segundo o arbítrio dos tomadores de serviço, detentores dos meios de produção e dos poderes econômicos e políticos.

Enquanto isso, a industrialização, favorecida pelo progresso científico e tecnológico, permitiu a concentração de trabalhadores no mesmo ambiente laboral. A oposição entre o operariado e o capital tornava-se mais evidente à medida que as condições de trabalho se tornavam mais deprimentes:

Num retrocesso que afrontava a dignidade humana, a duração normal do trabalho totalizava, comumente, 16 horas diárias; o desemprego atingiu níveis alarmantes e o valor dos salários decresceu. Para complementar o orçamento da família operária, a mulher e a criança ingressaram no mercado de trabalho, acentuando o desequilíbrio entre a oferta e a procura de emprego. E, assim, ampliada a mão de obra disponível, baixaram ainda mais os salários (Lei de bronze de LASSALE). Nem a liberdade formal nem a máquina libertaram o homem. (SÜSSEKIND, 2010, p. 15)

\footnotetext{
${ }^{1} \mathrm{O}$ suposto distanciamento e a posição aqui mencionados dizem respeito ao aspecto econômico da locação de serviços decorrente do modelo baseado na livre iniciativa, na regulação privada e na livre concorrência. Não se confunde com neutralidade estatal - inexistente mesmo no ideário liberal -, já que todo o arcabouço legal para a manutenção e a propagação da suposta igualdade entre os contratantes (tomadores de serviço e prestadores de serviço) foi assegurado pelo próprio Estado (especialmente por legitimar o capitalismo). O contraponto aqui apresentado serve como referência para a compreensão da mudança de foco no paradigma do Estado Social (a ser abordado no próximo item) - modelo político-econômico em que o Estado, com a finalidade de corrigir os desequilíbrios do modelo liberal, assume um papel de intervenção direta no sistema econômico.
} 
Quanto mais as fábricas se expandiam, mais se fortalecia a resistência dos trabalhadores contra a superexploração do capital. O compartilhamento de sofrimentos, lutas e reivindicações levou à formação de uma consciência de classe. Ao mesmo tempo em que o sistema fabril revolucionava o processo produtivo - intensificando a valorização da exploração da força de trabalho -, viabilizava a formação de uma classe razoavelmente homogênea:

\begin{abstract}
Ainda que a palavra de ordem fosse trabalhar até morrer, sem limites, concentrados nas fábricas, ao redor das máquinas, os trabalhadores se uniam, seguindo-se uma luta mais organizada do que outra, visando a manter salários, reduzir jornadas, melhorar as condições de trabalho. Nesse processo, foi se formando a consciência de si e, a seguir, a consciência de classe. (BIAVASCHI, 2016, p. 20-21)
\end{abstract}

A consciência de classe exteriorizou-se por meio de coalizões e, posteriormente, dos movimentos sindicais. A fase embrionária dos movimentos sindicais liga-se às associações secretas de resistência cuja existência é noticiada pela história dos países europeus:

A força de resistência da classe operária concentrou-se, pois, de início, no associacionismo secreto, agrupado à margem da lei, que o perseguia, mas, ainda assim, atuante na autotutela dos interesses de classe e movido pelo instinto de defesa coletiva contra a miséria e o aniquilamento. (GOMES; GOTTSCHALK, 1978, p. 3)

A organização do operariado tomou proporções maiores, e, em determinado momento, ficou visível que não bastava a luta por melhores condições de trabalho. O motivo da indignação e da insatisfação dos trabalhadores, coletivamente organizados, deixou de ser só os abusos dos patrões: a luta tornou-se aberta e clara contra o próprio sistema capitalista.

Inconformada com o poder do capital e com a ideologia liberal, a classe trabalhadora passou a defender a instauração de um modelo de sociedade que se mostrasse mais justo e equilibrado. Inaugurou-se, então, a defesa do socialismo (reivindicações históricas, de cunho político), sem que fosse abandonada a busca por melhorias no âmbito laboral (reivindicações imediatas, de natureza socioeconômica).

A união da classe operária, fortalecida pela conscientização grupal e impulsionada por uma ideologia contraposta à capitalista liberal, deu ensejo à estruturação das organizações sindicais e do Direito do Trabalho no fim do século XIX: 
Os movimentos grevistas, a ação direta pela sabotagem, ou pelo boicote; o movimento ludista na Inglaterra e em França; alguns convênios coletivos de existência precária, manifestados desde o início da história do movimento operário, são a prova evidente de que o impulso inicial dado para o aparecimento do Direito do Trabalho foi obra do próprio operário e não benevolência de filantropos, da classe patronal, ou do Estado. (GOMES; GOTTSCHALK, 1978, p. 3)

Percebe-se, portanto, que a ação do proletariado, dentro dos quadros adversos propiciados pela Revolução Industrial, foi o principal fator da construção do Direito do Trabalho.

É notável que os movimentos sociais ganharam corpo a ponto de a classe trabalhadora quase tomar o poder, a exemplo do que ocorreu em 1917 na Rússia, quando se criou a União Soviética. A organização operária, associada à propagação das ideologias contrapostas ao capitalismo, levou os governos liberais a reconhecer a força dos trabalhadores e sua relevância para a preservação do próprio sistema capitalista e, assim, a dar contornos mais sólidos a um ramo jurídico ocupado com a questão laboral.

A partir disso, o Estado Liberal foi substituído pelo Estado Social em resposta às demandas sociais e políticas oriundas da insatisfação com o modelo conduzido por um capitalismo que se mostrava cada vez mais monopolista. A mudança de paradigma deu-se a partir de inúmeras tensões da sociedade industrial que se formava, em nível mundial, com todos os seus efeitos reais, reivindicações, revoltas, greves, guerras, mutilações e mortes (SOUTO MAIOR; CORREIA, 2007, p. 19).

O ideário liberal deu lugar a um pensamento regulatório do capitalismo, construído a partir da doutrina econômica de John Maynard Keynes. Na lição de Delgado (2005, p. 79), as principais linhas de tal pensamento regulatório ligam-se a:

[...] uma política pública intervencionista, apta a garantir o equilíbrio, a estabilidade e o crescimento econômico, assegurando o ganho empresarial em face da combinação de fatores como a ampliação permanente de mercado, a renovação tecnológica e o financiamento a custo razoável, tudo permitindo a contrapartida empresarial e de todo o conjunto do sistema no sentido de assegurar a participação consistente dos trabalhadores nos benefícios conquistados pelo sistema econômico.

No paradigma social, o Estado deixou de ser omisso e se tornou provedor. Ele assumiu o papel de agente transformador e condutor da realidade social, sendo certo que, no século XX, a sociedade "não é mais apenas reduzida a um agrupamento de indivíduos proprietários privados, mas composta por uma sociedade conflituosa, dividida em vários 
grupos, classes, partidos e facções em disputa, cada qual buscando seus interesses" (FERNANDES, 2015, p. 68).

No plano constitucional, consagraram-se os chamados direitos fundamentais de segunda geração ou dimensão, afetos à igualdade substancial ou material e representativos da "preocupação de uns com a situação social e econômica de outros" (SOUTO MAIOR; CORREIA, 2007, p. 23). É importante registrar que a transposição paradigmática que representou a integração da solidariedade na ordem jurídica foi fomentada pelo chamado constitucionalismo social, movimento consistente na inserção, no texto de diversas Constituições, de normas ligadas à questão social.

O constitucionalismo social traduziu o reconhecimento da jusfundamentalidade dos direitos sociais (saúde, educação, previdência, transporte, habitação, entre outros) e econômicos (emprego, justa remuneração, entre outros) (MAGALHÃES, 2002, p. 27), sendo certo afirmar que houve uma ampliação e uma redefinição dos clássicos direitos do constitucionalismo liberal, bem como uma mudança completa nas bases interpretativas destes direitos. Observada principalmente após o fim da Primeira Guerra Mundial, a constitucionalização de direitos sociais decorreu da necessidade de se repensarem o Direito e o Estado diante do desgaste da ideologia liberal com suas promessas irrealizadas (FERNANDES, 2015, p. 67) e com a desigualdade e a exclusão dela consequentes.

Essa constitucionalização representou um compromisso estatal de implementação dos interesses sociais (o Estado passou a ser sujeito passivo dessa obrigação):

Juridicamente, o Estado deixa de ser um mero legitimador dos interesses dos dominantes e transfigura-se em autêntico Estado Social (pelo menos no prisma do direito). Em se tratando a Constituição de documento no qual se concretiza a unidade política de uma nação, há verdadeiro reconhecimento de que o espaço político não pode desconsiderar os direitos sociais. (SOUTO MAIOR; CORREIA, 2007, p. 22)

Nota-se que o constitucionalismo social materializou a busca pela conversão dos anseios sociais em direito positivo, com sua elevação à categoria de normas constitucionais fundamentais. As Constituições passaram a trazer em seu bojo, além do estatuto político, normas programáticas político-sociais, que regulavam a ordenação social e as formas de participação da comunidade, inclusive no processo produtivo, e ditavam os fundamentos das relações interpessoais e grupais. 
O Direito do Trabalho robusteceu-se e revelou-se um importante instrumento jurídico de distribuição de renda e democratização do poder (COSTA; GOMES, 2013, p. 259). O intervencionismo estatal, característica marcante do Estado Social, abraçou o conflito entre capital e trabalho e, no âmbito do Direito, edificou uma regulação especializada para as relações trabalhistas, constitucionalmente amparada, "contribuindo para ampliar a dignidade dos trabalhadores, especialmente nos países centrais" (DELGADO, 2006, p. 158). Ressaltam Delgado e Delgado (2012, p. 40):

\footnotetext{
Essa incorporação do segmento jurídico-trabalhista também fazia avançar, agora mediante status constitucional, o processo anterior de reconhecimento e institucionalização da separação do ser humano e de seu trabalho perante o conceito e a realidade do direito de propriedade.
}

Desse modo, houve um grande avanço para a consolidação do trabalho como um processo de "mudança cultural, jurídica, social e econômica de grande relevância, para se tornar valor especialmente celebrado pela ordem jurídica e constitucional” (DELGADO; DELGADO, 2012, p. 40).

É importante mencionar que a Organização Internacional do Trabalho (OIT) - criada pelo Tratado de Versailles em 1919 - foi marco decisivo no processo de estruturação do Direito do Trabalho como ramo jurídico autônomo. Ao negar, em sua Constituição, a natureza mercantil do trabalho, a OIT buscou solidificar, no plano internacional, o caráter moderno e social da normatização trabalhista, que, "tendo na dignidade humana o ponto de partida e a condição humana como tema central, marcou diferença ao unir o elemento humano, pessoal, ao social, coletivo, imbricando-os" (BIAVASCHI, 2016, p. 21).

Embora a estruturação do ramo juslaboral tenha refletido a política intervencionista do Estado Social, não podem ser esquecidos os embates travados pela classe operária em prol de uma normatização que desmercantilizasse a força de trabalho e revigorasse a condição humana dos trabalhadores, reificados pelo capital. $\mathrm{O}$ espaço para o nascimento e desenvolvimento do Direito do Trabalho foi aberto pelos movimentos sociais e pelas reivindicações operárias, ocorridos especialmente no fim do século XIX e início do século $\mathrm{XX}$, influenciados por ideologias contrapostas à capitalista (socialismo e anarquismo, por exemplo), como anteriormente exposto.

Com relação à organização operária ou, mais precisamente, à organização sindical no contexto do novo paradigma de Estado, tem-se que o constitucionalismo social permitiu o 
avanço da ideia de que a liberdade é elementar na esfera coletiva trabalhista. No mesmo sentido, a OIT, ao adotar, desde o seu nascimento, a liberdade sindical como princípio norteador das relações laborais coletivas, reconheceu a suma importância do papel desempenhado pelas entidades sindicais na construção e no aprimoramento do Direito do Trabalho e, consequentemente, na efetivação da justiça social, da igualdade substancial e da democracia.

\section{A LIBERDADE SINDICAL COMO DIRETO HUMANO E FUNDAMENTAL: O SINDICALISMO COMO INSTRUMENTO DE REALIZAÇÃO DO ESTADO DEMOCRÁTICO DE DIREITO}

No Estado Liberal, a liberdade havia sido consagrada só no plano individual, já que a ideia do associativismo e, pois, de uma liberdade afeta à coletividade, era incompatível com a lógica do individualismo preponderante naquele paradigma. Um longo caminho foi percorrido até a superação do pensamento liberal e, assim, até o reconhecimento da liberdade associativa e sindical como direito humano e fundamental.

De início, é importante que se conceituem direito humano e direito fundamental. A doutrina não é unânime ao diferenciar tais expressões, mas vale lembrar que "não há dúvidas de que os direitos fundamentais, de certa forma, são também sempre direitos humanos, no sentido de que seu titular sempre será o ser humano, ainda que representado por entes coletivos (grupos, povos, nações, Estado)" (SARLET, 2009, p. 29).

Os direitos humanos, cuja gênese pode ser atribuída à difusão das matrizes filosóficas jusnaturalistas e iluministas nos séculos XVII e XVIII, conectam-se à ideia de que o homem possui direitos imprescritíveis e inalienáveis pelo simples fato de existir enquanto tal. Assim, em essência, os direitos humanos não dependem de positivação:

\footnotetext{
A primeira questão, referente à existência dos Direitos Humanos, foi justificada originariamente pelo jusnaturalismo, corrente do pensamento filosófico que considerava os homens dotados de direitos naturais anteriores à formação da sociedade, direitos que lhes pertenciam, pura e simplesmente, pelo fato de serem humanos. (DELGADO, 2011, p. 61)
}

Os direitos considerados intrínsecos ao homem em razão da sua natureza humana acabaram passando por três marcos históricos: "o da conscientização da existência de direitos 
naturais, evidentes à razão; o da positivação desses direitos no ordenamento constitucional; e, finalmente, o da efetivação dos direitos, eis que reconhecidos e concretizados no plano social [...]” (DELGADO, 2011, p. 61). É, portanto, fato que, além de reconhecidos, os direitos humanos foram positivados.

O critério definitivo para a distinção entre direito humano e direito fundamental é a natureza do documento positivador do direito. Esclarece Sarlet (2009, p. 29) que fundamentais são os direitos do homem reconhecidos e constitucionalmente positivados por um Estado, enquanto a expressão direitos humanos guarda uma relação:

[...] com os documentos de direito internacional, por referir-se àquelas posições jurídicas que se reconhecem ao ser humano como tal, independentemente de sua vinculação com determinada ordem constitucional, e que, portanto, aspiram à validade universal, para todos os povos e tempos, de tal sorte que revelam um inequívoco caráter supranacional (internacional).

Assim, fundamentais são os direitos humanos reconhecidos pelo Estado e protegidos por sua Constituição; são aqueles selecionados pelo legislador para integrar o eixo jurídicoconstitucional-substancial, do qual emanará a legislação ordinária; são "direitos do homem garantidos jurídico-institucionalmente e limitados espacio-temporalmente" (CANOTILHO, 2003, p. 393). É possível, assim, “falar-se em direitos humanos 'fundamentalizados' em oposição a direitos humanos 'não fundamentalizados' por um determinado Estado" (MORAES FILHO, 1978, p. 42). Nessa ordem de ideias, é perceptível que os direitos fundamentais podem variar segundo a ideologia, o Estado e os valores celebrados pela Constituição.

Contudo, direitos humanos e fundamentais não se diferem apenas quanto à positivação. Com relação aos titulares, os direitos humanos são reconhecidos aos seres humanos sem distinção, enquanto os direitos fundamentais, por serem positivados, possuem como titulares só os cidadãos do Estado que promove a positivação no seu ordenamento interno. No que se refere à eficácia, os direitos fundamentais, em regra, são aplicáveis por força das próprias Constituições que os consagram, ao passo que a efetivação dos direitos humanos depende do status jurídico a eles atribuído segundo as regras do ordenamento jurídico recepcionante.

Feita a conceituação proposta, percebe-se que não basta fundamentalizar os direitos do homem. A principal tarefa é protegê-los sempre. 
Retomando-se a análise da liberdade cara à esfera coletiva do ramo justrabalhista à luz da teoria dos direitos humanos e fundamentais, tem-se que, embora a liberdade sindical derive da noção de liberdade individual, só a partir da implantação do Estado Social aquela ganhou espaço no cenário jurídico. Vale frisar que, instituído o paradigma social de Estado, os sindicatos deixaram a posição de associações clandestinas e criminosas para se tornarem protagonistas da construção dos direitos trabalhistas, o que não seria possível num contexto de controle e repressão do sindicalismo.

A Constituição Mexicana de 1917, em seu artigo 123, inciso XVI ${ }^{2}$, garantiu o direito de associação sindical a empregados e empresários, para a defesa de seus respectivos interesses. A Constituição Soviética de 1918, em seu artigo $16^{3}$, apoiou toda e qualquer tendência direcionada à união e à organização dos trabalhadores. No mesmo sentido, a Constituição Alemã de 1919 (Constituição de Weimar), em seu artigo 1594, garantiu expressamente a liberdade de associação para a defesa das condições de trabalho e econômicas, considerando ilegais medidas que limitassem ou impedissem tal liberdade. Esses são exemplos de como a liberdade sindical teve identificada a sua relevância (consubstanciada pelo reconhecimento da sua jusfundamentalidade) na época do constitucionalismo social.

De fato, como elementos essenciais à construção e à evolução do Direito do Trabalho, a liberdade no âmbito coletivo e a atuação sindical dela decorrente passaram a ser vistas, de forma clara, como importantes instrumentos de promoção de equilíbrio nas relações entre capital e trabalho. Entendeu-se que a liberdade não mais poderia ser afastada da justiça social, sendo infrutífero cogitar-se, também, em justiça social sem liberdade - afinal, todos os direitos humanos constituem um complexo integral, único e indivisível (PIOVESAN, 2002, p. 73-75).

É importante registrar que foi depois da Segunda Guerra Mundial que a internacionalização dos direitos humanos se consolidou, com as importantes mudanças que marcaram o Direito Internacional: "O Direito Internacional pode ser classificado como o Direito anterior à $2^{\mathrm{a}}$ Guerra Mundial e o Direito posterior a ela. Em 1945, a vitória dos aliados

\footnotetext{
2 "Tanto los obreros como los empresarios tendran derecho para coaligarse en defensa de sus respectivos intereses, formando sindicatos, asociaciones profesionales, etc." (MEXICO, 05 fev. 1917).

3 "The Russian Socialist Federated Soviet Republic, having crushed the economic and political power of the propertied classes, and having thus abolished all obstacles which interfered with the freedom of organization and action of the workers and peasants, offers assistance, material and other, to the workers and the poorest peasantry in their effort to unite and organize" (SOVIET REPUBLIC, 10 jul. 1918).

4 "The right to form unions and to improve conditions at work as well as in the economy is guaranteed to every individual and to all occupations. All agreements and measures limiting or obstructing this right are illegal" (GERMANY, 11 ago. 1919).
} 
introduziu uma nova ordem com importantes transformações no Direito Internacional." (HENKIN apud PIOVESAN, 2006, p. 7). O Direito do Trabalho, nesse cenário, transformouse num verdadeiro instrumento internacionalizado de direitos humanos, na medida em que a jusfundamentalidade dos direitos sociais (direitos de segunda dimensão) foi amplamente reconhecida.

A partir daí, em 1948, editou-se a Declaração Universal dos Direitos Humanos, que, já em seu preâmbulo, afirmou que "o reconhecimento da dignidade inerente a todos os membros da família humana e de seus direitos iguais e inalienáveis é o fundamento da liberdade, da justiça e da paz no mundo.” (ORGANIZAÇÃO DAS NAÇÕES UNIDAS, 1948) Indo além, fazendo com que a liberdade sindical ultrapassasse o plano jurídicotrabalhista, a Declaração estabeleceu inúmeros preceitos ligados à valorização de um trabalho digno e às liberdades de reunião e filiação. ${ }^{5}$

Percebe-se, pela redação da Declaração Universal dos Direitos Humanos, que não só a liberdade individual foi elevada ao patamar de direito humano, mas também a liberdade de associação, o que garantiu um substrato essencial para o seu reconhecimento como direito fundamental por vários Estados. Admitindo-se o importante papel da associação (em especial da sindical) na idealização das concepções de liberdades coletivas, a liberdade sindical pôde ser tomada como elemento primordial para a edificação de uma sociedade mais justa e igualitária no sentido substancial.

A liberdade sindical, já consagrada no plano internacional como direito humano, também teve destaque em outros instrumentos, como na Convenção Europeia de Direitos Humanos de 1950.

Seguindo a mesma tendência, o Pacto de Direitos Civis e Políticos e o Pacto de Direitos Econômicos, Sociais e Culturais, diplomas internacionais aprovados pela XXI Assembleia Geral das Nações Unidas em 1966, também confirmaram a natureza de direito humano atribuída à liberdade sindical (referidos Pactos ainda vedaram a ingerência e a intervenção dos poderes públicos na organização sindical, garantindo, por consequência, o

\footnotetext{
5 “Artigo $20^{\circ} 1$. Toda a pessoa tem direito à liberdade de reunião e de associação pacíficas. 2. Ninguém pode ser obrigado a fazer parte de uma associação. [...] Artigo $23^{\circ}$ 1. Toda a pessoa tem direito ao trabalho, à livre escolha do trabalho, a condições equitativas e satisfatórias de trabalho e à proteção contra o desemprego. 2 . Todos têm direito, sem discriminação alguma, a salário igual por trabalho igual. 3. Quem trabalha tem direito a uma remuneração equitativa e satisfatória, que lhe permita e à sua família uma existência conforme com a dignidade humana, e completada, se possível, por todos os outros meios de proteção social. 4.Toda a pessoa tem o direito de fundar com outras pessoas sindicatos e de se filiar em sindicatos para defesa dos seus interesses" (ORGANIZAÇÃO DAS NAÇÕES UNIDAS, 1948).
} 
livre exercício da atividade das entidades). A orientação repetiu-se no Pacto de São José da Costa Rica de 1969 (Convenção Americana de Direitos Humanos).

A liberdade sindical, portanto, é indubitavelmente considerada direito humano. Ademais, a previsão em incontáveis padrões constitucionais e em vários documentos internacionais comprova a inafastável acepção de jusfundamentalidade assumida pela liberdade sindical no decorrer do século XX.

Essa defesa da liberdade na esfera do Direito Coletivo do Trabalho, construída à luz do paradigma social, desenvolveu-se até a instauração do Estado Democrático de Direito. Firmou-se, no paradigma democrático, uma nova concepção da liberdade sindical, que a registra não só como direito humano e fundamental (decorrente do reconhecimento internacional e da constitucionalização dos diretos sociais), mas também como elemento diretamente vinculado aos direitos fundamentais de fraternidade (direitos de terceira dimensão, titularizados pela coletividade).

\section{A RESSIGNIFICAÇÃo DO SINDICALISMO NO ESTADO DEMOCRÁTICO DE DIREITO}

O paradigma do Estado Social deu lugar ao do Estado Democrático de Direito, prevalecente na atualidade ${ }^{6}$, fundado num tripé conceitual inovador: "pessoa humana, com sua dignidade; sociedade política, concebida como democrática e includente; sociedade civil, também concebida como democrática e includente" (DELGADO, 2012, p. 46).

\footnotetext{
${ }^{6}$ É bom ressaltar que isso não significa que os efeitos do neoliberalismo e sua potencial hegemonia devem ser ignorados. O Brasil por exemplo, que constitucionalizou direitos sociais apenas em 1988, descobriu tardiamente os sentidos do Estado Democrático de Direito e já sofre os efeitos políticos, econômicos e ideológicos do neoliberalismo. Merece destaque a colocação de Streck e Morais (2014, p. 38): "É evidente, pois, que, em países como o Brasil, onde o Estado Social não existiu, o agente principal de toda política social deve ser o Estado. As políticas neoliberais, que visam a minimizar o Estado, não apontarão para a realização de tarefas antitéticas a sua natureza. Veja-se o exemplo ocorrido na França, onde, após um avanço dos neoliberais, na década de 1990, a pressão popular exigiu a volta das políticas típicas do Estado Providência. É este, pois, o dilema: quanto mais necessitamos de políticas públicas, em face da miséria que se avoluma, mais o Estado, único agente que poderia erradicar as desigualdades sociais, se encolhe! Tudo isso acontece na contramão do que estabelece o ordenamento constitucional brasileiro, que aponta para um Estado forte, intervencionista e regulador, na esteira daquilo que, contemporaneamente, se entende como Estado Democrático de Direito. O Direito recupera, pois, sua especificidade. No Estado Democrático de Direito, ocorre a secularização do Direito. Desse modo, é razoável afirmar que o Direito, legado da modernidade - até porque temos uma Constituição democrática -, deve ser visto, hoje, como um campo necessário de luta para implantação das promessas modernas".
} 
Na verdade, o Estado Democrático de Direito pode ser percebido como uma fórmula aprofundada do Welfare State e do Estado de Direito ${ }^{7}$, ou seja, se de um lado manteve em voga a questão social, de outro inseriu na equação a questão da igualdade. Diante da incapacidade do Estado Social de oferecer condições concretas para a efetivação dos direitos sociais, o Estado Democrático de Direito permitiu o desenvolvimento de um conceito que une, à lógica do Estado de Direito, a legitimação democrática do poder:

Estado de direito e democracia correspondem a dois modos de ver a liberdade. No Estado de direito concebe-se a liberdade como liberdade negativa, ou seja, uma "liberdade de defesa" ou de "distanciação" perante o Estado. É uma liberdade liberal que "curva" o poder. Ao Estado democrático estaria inerente a liberdade positiva, isto é, a liberdade assente no exercício democrático do poder. É a liberdade democrática que legitima o poder. (CANOTILHO, 2003, p. 101)

Assim, o princípio da soberania popular seria a única forma de assegurar o direito à participação igualitária na formação da democracia. Desse modo, Canotilho (2003, p. 102) conclui que esse princípio, efetivamente concretizado por meio de procedimentos juridicamente regulados, "serve de 'charneira' entre o 'Estado de direito' e o 'Estado democrático' possibilitando a compreensão da moderna fórmula Estado de direito democrático".

A transformação da realidade passa a ser o conteúdo do Estado Democrático de Direito, que busca materializar (efetiva concretização da igualdade) a dignidade do homem, que, por sua vez, é o instigador da atuação pública (propagação dos valores democráticos sobre os fundamentos que compõem a ordem jurídica do Estado) (STRECK; MORAIS, 2014, p. 45). O paradigma da democracia, incrustrado no Estado de Direito, pretende, assim, não apenas fomentar a igualdade, mas firmar a norma como um verdadeiro instrumento de transformação social.

\footnotetext{
${ }^{7}$ Quanto à construção de um Estado de Direito - que perpassa pelos paradigmas liberal, social e democrático analisados - e suas características, destaca-se: "Com efeito, no plano teórico, o Estado de Direito emerge como uma construção própria à segunda metade do século XIX, nascendo na Alemanha - como 'Rechtstaat' - e, posteriormente, sendo incorporado à doutrina francesa, em ambos como um debate apropriado pelos juristas e vinculado a uma percepção de hierarquia das regras jurídicas, com o objetivo de enquadrar e limitar o poder do Estado pelo Direito. [...] Pode-se, então, apontar três visões próprias a este fenômeno: A - Visão Formal, pela qual se vincula a ação do Estado ao Direito, ou seja, a atuação estatal jurídica, exercitando-se através de regras jurídicas; B - Visão Hierárquica, na qual a estruturação escalonada da ordem jurídica impõe ao Estado sua sujeição ao Direito; C - Visão Material, que implica a imposição de atributos intrínsecos ao Direito, ou seja, aqui, a ordem jurídica estatal produz-se tendo certa substancialidade como própria. Há uma qualificação do Estado pelo Direito e deste por seu conteúdo". (STRECK; MORAIS, 2014, p. 40-41).
} 
De acordo com Delgado e Delgado (2012, p. 25), o Estado Democrático de Direito é o mais evoluído, sob a ótica da história política, social, cultural e econômica, na dinâmica dos direitos humanos, pois se baseia em critérios de pluralidade e de reconhecimento universal de direitos.

A partir da doutrina de Joaquim Carlos Salgado, os autores explicam que a fundamentação teórica do novo paradigma é subsidiada: pelo reconhecimento da soberania do Estado (princípio ontológico); pelos baluartes constitucionais da legalidade, do direito adquirido, da proteção jurídica e das garantias processuais, com o intuito de efetivação da segurança jurídica em sentido amplo (princípios lógicos); e pela finalidade ética estatal de declarar, garantir e realizar os direitos fundamentais (princípios axiológicos) (DELGADO; DELGADO, 2012, p. 27).

Os chamados direitos fundamentais de terceira geração ou dimensão, de natureza transindividual (titularizados pela coletividade, ou seja, de destinatários coletivos e difusos) e ligados à fraternidade, solidificaram-se no contexto do Estado Democrático de Direito. Tratase dos direitos à paz, ao meio ambiente, à comunicação, à autodeterminação dos povos, entre outros (BONAVIDES, 2003, p. 569).

Na esfera do Direito Constitucional, a transição para o novo paradigma foi marcada pelo avanço e pela consolidação do fenômeno conhecido como neoconstitucionalismo ${ }^{8}$. Esse fenômeno impulsionou amplas transformações no campo jurídico, especialmente por meio da reaproximação entre direito e moral, do reconhecimento da centralidade dos direitos fundamentais e do desenvolvimento de uma nova dogmática de interpretação da Constituição, que teve amplamente reconhecida a sua força normativa (ORLANDO; SOUZA, 2013).

O Estado Democrático de Direito também inaugurou o chamado constitucionalismo procedimental. Sobre a caracterização reflexivo-procedimental da Constituição, merece destaque o conceito proposto por Fernandes (2015, p. 71), com base na teoria discursiva da democracia de Jürgen Habermas:

Temos que a Constituição deve ser compreendida como a prefiguração de um sistema de direitos fundamentais que representam as condições procedimentais para a institucionalização da democracia, nos âmbitos e nas perspectivas específicas do processo legislativo, jurisdicional e administrativo, e que garante, ainda, espaços públicos informais de geração da vontade e das opiniões políticas.

\footnotetext{
${ }^{8}$ Tal fenômeno surgiu na Itália e na Alemanha logo depois da Segunda Guerra Mundial, como decorrência da percepção de que maiorias políticas podem perpetrar barbáries; mais tarde, desenvolveu-se em Portugal e na Espanha (BARROSO, 2007).
} 
O princípio jurídico-constitucional da democracia, otimizado segundo a concepção de cada um dos processos mencionados pelo autor, significa a "participação em igualdade de direitos e de oportunidades, daqueles que serão afetados pelas decisões, nos procedimentos deliberativos que as preparam" (FERNANDES, 2015, p. 71).

No âmbito juslaboral, a fundamentalidade e a universalidade do direito ao trabalho digno tornaram-se o norte das relações trabalhistas como consequência da orientação proposta pelo "valor-fonte da dignidade" (DELGADO, 2012, p. 27). Em verdade, a dignidade da pessoa humana, alicerce do Estado Democrático de Direito, passou a ser vista como a causa e a consequência, o ponto de partida e o de chegada da proteção conferida pelas normas do Direito do Trabalho.

No campo coletivo, em tempos de consagração de direitos fundamentais transindividuais, ganha destaque o papel das entidades sindicais enquanto defensoras dos direitos e interesses dos seus representados coletivamente considerados. Os valores da democracia e da inclusão, caros ao Estado Democrático de Direito, tornam necessário o repensar da organização sindical (que deve refletir aqueles valores, mormente diante do reconhecimento da liberdade associativa e sindical como direito humano e fundamental) e da atuação das entidades sindicais na contenção do ideário neoliberal, no aprimoramento do Direito do Trabalho, especialmente pela via da negociação coletiva, e na efetivação do paradigma de Estado.

Nessa perspectiva, a conexão entre a liberdade sindical e os valores afetos ao paradigma democrático de Estado é facilmente notável. Isso porque a lógica da organização sindical livre parte exatamente das noções de coletividade, de união em prol do bem comum e de participação dos trabalhadores nos centros de poder e na construção do direito. Com isso, assegura-se ao sindicato um papel muito mais amplo do que a simples representação justrabalhista-setorial:

A função de representação destes interesses pelas organizações sindicais não se esgota na sua defesa frente ao empregador, público ou privado. Em uma noção mais abrangente, as organizações sindicais podem mediar situações que requerem a presença dos poderes públicos como contraparte, assim como assumem funções de co-determinação de interesses sociais. (GRAU, 1999, p. 144) 
Isso impede, portanto, a "imposição de um horizonte setorial aos sindicatos", já que sua função "não se limita à troca básica da prestação de trabalho" (GRAU, 1999, p. 144). Em suma, do ponto de vista constitucional, o sindicato "se prefigura sua atuação no marco da sociedade politica global e disto se deduz que o objetivo do sindicato também é 'o conjunto do sistema político, no qual pretende afirmar fortemente seu protagonismo"” (GRAU, 1999, p. 144).

Trata-se, assim, de um sujeito coletivo com potencial para desenvolver um diálogo intra-governamental na construção de negociações legislativas ou fontes normativas sobre matérias econômicas e sociais, sem abrir mão das medidas de pressão coletiva constitucionalmente asseguradas.

Sendo o Estado Democrático de Direito fundado na pluralidade ${ }^{9}$, no reconhecimento universal de direitos, na inclusão, na cidadania e na dignidade da pessoa humana, é certo que, nesse paradigma de Estado, o Direito do Trabalho (e o sindicalismo livre, como seu elemento estruturante) ocupa posição central.

São impensáveis “a estrutura e a operação prática de um efetivo Estado Democrático de Direito sem a presença de um Direito do Trabalho relevante na ordem jurídica e na experiência concreta dos respectivos Estado e sociedade civil” (DELGADO; DELGADO, 2012, p. 47). Nesse sentido, a democratização da sociedade civil foi estabelecida pela disseminação econômica e social de um Direito do Trabalho eficiente, o que permitiu promover valores essenciais, como a:

[...] garantia da dignidade da pessoa humana na vida social, garantia da prevalência dos direitos fundamentais da pessoa humana no plano da sociedade, subordinação da propriedade à sua função social, garantia da valorização do trabalho na atividade econômica e do primado do trabalho e especialmente do emprego na ordem social [...]. (DELGADO; DELGADO, 2012, p. 48)

Se os sindicatos são a voz dos trabalhadores na busca da sua inclusão social e cidadania $^{10}$, a organização e a atuação daqueles não podem estar sujeitas a nenhum tipo de

\footnotetext{
${ }^{9}$ A Carta brasileira de 1988, a título de exemplo, ao inserir o sindicato como sujeito ativo da produção normativa (em especial por meio das negociações coletivas $-\operatorname{artigos~} 7^{\circ}$ e $8^{\circ}$ ) assegurou o reconhecimento estatal do pluralismo jurídico, o que, por conseguinte, permite concluir que os sujeitos coletivos também possuem um papel relevante na aplicação e na interpretação da norma.

${ }_{10}$ Nesse mesmo sentido e como essência de uma Constituição cidadã - que insere, em seu bojo, os direitos trabalhistas e sociais -, Santos (1995, p. 135) destaca que "isto significa valorizar o que de melhor a cultura operária produziu: uma ambição de cidadania patilhável por toda a sociedade" o que permite, em última análise, "uma transferência progressiva da identidade operária para identidade cidadã".
} 
controle por parte do seu adversário na luta - o poder econômico (ainda que de forma indireta, por meio do Estado). A garantia da liberdade no âmbito justrabalhista coletivo tem, portanto, efeito claramente emancipatório sobre o Direito do Trabalho como um todo: entidades sindicais livres conseguem agir de forma a promover conquistas que reflitam o aprimoramento das relações laborais e a melhoria da condição social dos que vivem do trabalho.

Como houve o reconhecimento, pelo Estado Democrático de Direito, do sindicalismo como elemento central, inclusive de democratização do poder, o Estado não pode deixar de assegurar ao sindicato, sujeito promotor da igualdade substancial, a autonomia e a unidade de organização (consectários axiológicos da liberdade sindical).

O sindicato, revelado como instrumento para a expressão dos poderes sociais da classe trabalhadora - e, com isso, identificador e defensor de uma democracia social e plural merece uma abordagem promocional e incentivadora por parte do Estado (MARTÍNEZ, 1980, p. 207). Nessa perspectiva, a liberdade sindical é o sustentáculo do sindicalismo efetivamente comprometido com o caráter tuitivo do ramo juslaboral e se apresenta como verdadeiro instrumento de realização do próprio Estado Democrático de Direito.

\section{CONSIDERAÇÕES FINAIS}

A consagração dos direitos fundamentais de terceira dimensão, a identificação da jusfundamentalidade dos direitos sociais trabalhistas, bem como o alicerçamento da dignidade da pessoa humana e do valor social do trabalho como corolários do Estado Democrático de Direito, fizeram perceber o papel de destaque dado às entidades sindicais como agentes para a promoção de uma atuação inclusiva e progressiva. Os valores da democracia e da inclusão tornaram necessário o repensar da organização e da atuação das entidades sindicais, especialmente para o aprimoramento do Direito do Trabalho e para a efetivação dos novos paradigmas do Estado.

Há, nesse sentido, uma conexão direta entre o paradigma democrático de Estado e a liberdade sindical. Uma organização sindical livre pressupõe a união em prol do bem comum e a participação dos trabalhadores na construção de seus direitos, pois a democratização da sociedade civil se encontra incrustrada, essencialmente, na consolidação econômica e social do Direito do Trabalho. Essa abertura constitucional possibilitou, então, inserir os sindicatos 
nos centros de poder do Estado Democrático de Direito, já que a classe trabalhadora tem, no sujeito coletivo, seu maior expoente.

A fundamentalidade do sindicalismo para a implementação e para o aperfeiçoamento da democracia pode ser percebida, também, a partir da consagração da liberdade sindical como direito humano e fundamental. Não sem razão, as principais Constituições contemporâneas incorporaram, em seu arcabouço normativo, os direitos trabalhistas e princípios sindicais a fim de efetivá-los.

Desse modo, a liberdade sindical permite que as entidades ajam de forma a promover conquistas que reflitam o aprimoramento das relações laborais e da cidadania. Por isso, o reconhecimento da centralidade do sindicalismo por esse novo paradigma exige que o Estado assegure sua autonomia e sua unidade de organização. Assim, a consolidação da liberdade sindical pode ser percebida como um compromisso teleológico e axiológico do Direito do Trabalho edificado por meio dos próprios atores sociais que pretende emancipar.

\section{REFERÊNCIAS}

BARROSO, Luis Roberto. Neoconstitucionalismo e constitucionalização do direito: o triunfo tardio do direito constitucional do Brasil. In: SOUZA NETO, Cláudio Pereira de;

SARMENTO, Daniel. A constitucionalização do direito: fundamentos teóricos e aplicações específicas. Rio de Janeiro: Lumen Juris, 2007.

BIAVASCHI, Magda Barros. A construção das normas de proteção social ao trabalho e seus fundamentos. In: ROCHA, Cláudio Jannotti da; VIANA, Márcio Túlio (Coord.). Como aplicar a CLT à luz da constituição: alternativas para os que militam no foro trabalhista. São Paulo: LTr, 2016.

BOBBIO, Norberto. O futuro da democracia. Trad. Marco Aurélio Nogueira. 8. ed. São Paulo: Paz e Terra, 2002.

BONAVIDES, Paulo. Curso de direito constitucional. 13. ed. São Paulo: Malheiros, 2003.

CANOTILHO, José Joaquim Gomes. Direito constitucional e teoria da constituição. 7. ed. Coimbra: Almedina, 2003.

COSTA, Cynthia Lessa; GOMES, Maíra Neiva. Direito do trabalho e constitucionalismo. In: MURADAS, Daniela; MELLO, Roberta Dantas de; COURA, Solange Barbosa de Castro (Coord.). Trabalho e justiça social: um tributo a Maurício Godinho Delgado. São Paulo: LTr, 2013.

DELGADO, Gabriela Neves. Direito fundamental ao trabalho digno. São Paulo: LTr, 2006. 
DELGADO, Gabriela Neves. Direitos humanos dos trabalhadores: perspectivas de análise a partir dos princípios internacionais do direito do trabalho e do direito previdenciário. Revista do TST, Brasília, v. 77, n. 3, p. 59-76, jul./set. 2011.

DELGADO, Gabriela Neves; DELGADO, Maurício Godinho. Constituição da república e direitos fundamentais: dignidade da pessoa humana, justiça social e direito do trabalho. São Paulo: LTr, 2012.

DELGADO, Maurício Godinho. Capitalismo, trabalho e emprego: entre o paradigma da destruição e os caminhos de reconstrução. São Paulo: LTr, 2005.

DELGADO, Maurício Godinho. Curso de direito do trabalho. 15. ed. São Paulo: LTr, 2016.

EWALD, François. Histoire de l'etat providence: les origines de la solidarité. Paris: Grasset, 1996.

FERNANDES, Bernardo Gonçalves. Curso de direito constitucional. 7. ed. Salvador: Juspodivm, 2015.

GERMANY. The Reich Constitution of August 11th, 1919 (Weimar Constitution).

Germany, 11 ago. 1919. Disponível em: 〈http://www.zum.de/psm/weimar/weimar_vve.php>. Acesso em: 15 mai 2017.

GOMES, Orlando; GOTTSCHALK, Elson. Curso de direito do trabalho. 7. ed. São Paulo: Forense, 1978. v. I.

GRAU, Antonio Baylos. Direito do trabalho: modelo para armar. Tradução de Flávio Benites e Cristina Schultz. São Paulo: LTr, 1999.

HOBSBAWM, Eric J. Mundos do trabalho: novos estudos sobre história operária. 4. ed. Tradução de Waldea Barcellos e Sandra Bedran. São Paulo: Paz e Terra, 2000.

HUNT, E. K.; SHERMAN, Howard J.. História do pensamento econômico. Trad. Jaime Larry Benchimol. 5. ed. Petrópolis: Vozes, 1986.

MACHADO, Gustavo Seferian Scheffer. A ideologia do contrato de trabalho. São Paulo: LTr, 2016.

MAGALHÃES, José Luiz Quadros de. Direito constitucional: tomo II. Belo Horizonte: Mandamentos, 2002.

MARTÍNEZ, José Enrique Serrano. El convenio colectivo de franja en el ordenamiento espanhol. In: Lecciones de derecho del trabajo en homenaje a los profesores Bayón Chacón y Del Peso y Calvo. Madrid: Faculdad de Derecho de la Universidad Complutense, 1980, p. 199-268. 
MEXICO. Constitucion Politica de los Estados Unidos Mexicanos que Reforma la de 5 de febrero del 1857. Diário Oficial, Mexico, 05 fev. 1917. Disponível em:

<http://www.diputados.gob.mx/LeyesBiblio/ref/cpeum/CPEUM_orig_05feb1917.pdf>.

Acesso em: 15 mai 2017.

MORAES FILHO, Evaristo de. O problema do sindicato único no Brasil. São Paulo: Alfa Ômega, 1978.

ORGANIZAÇÃO DAS NAÇÕES UNIDAS. Declaração universal dos direitos humanos. 1948. Disponível em: 〈http://www.dudh.org.br/wp-content/uploads/2014/12/dudh.pdf >. Acesso em: 15 mai 2017.

ORLANDO, Marielen Paura; SOUZA, Tiago Clemente. Neoconstitucionalismo, a "virada hartiana" e o ativismo judicial: leitura a partir do atual paradigma jurídico. In: ADEODATO, João Maurício Leitão; BORGES, Alexandre Walmott; TOLEDO, Iara Rodrigues de (Coord.). Hermenêutica. Florianópolis: FUNJAB, 2013. Disponível em:

<http://www.publicadireito.com.br/artigos/?cod=b0eb9a95e8b085e4>. Acesso em: 15 mai 2017.

PIOVESAN, Flávia (Coord.). Direitos humanos, globalização econômica e integração regional: desafios do direito constitucional internacional. São Paulo: Max Limonad, 2002.

PIOVESAN, Flávia. Direitos humanos e justiça internacional. São Paulo: Saraiva, 2006.

RENAULT, Luiz Otávio Linhares. Que é isto - o direito do trabalho? In: PIMENTA, José Roberto Freire [et al.] (Coord.). Direito do trabalho: evolução, crise, perspectivas. São Paulo: LTr, 2004.

SANTOS, Boaventura de Sousa. Teses para a renovação do sindicalismo em Portugal, seguidas de um apelo. Vértice, n. 68, p. 132-139, set./out. 1995.

SARLET, Ingo Wolfgang. A eficácia dos direitos fundamentais: uma teoria geral dos direitos fundamentais na perspectiva constitucional. 10. ed. Porto Alegre: Livraria do Advogado, 2009.

SOUTO MAIOR, Jorge Luiz; CORREIA, Marcus Orione Gonçalves. O que é direito social? In: CORREIA, Marcus Orione Gonçalves (Org.). Curso de direito do trabalho: teoria geral do direito do trabalho. São Paulo: LTr, 2007.v. I.

SOVIET REPUBLIC. 1918 Constitution of the Russian Soviet Federated Socialist

Republic. Republic Soviet, 10 jul. 1918. Disponível em:

<https://www.marxists.org/history/ussr/government/constitution/1918/>. Acesso em: 15 mai 2017.

STRECK, Lênio Luiz; MORAIS, José Luis Bolsan de. Ciência política \& teoria do estado. 8. ed. rev. atual. Porto Alegre: Livraria do Advogado, 2014.

SÜSSEKIND, Arnaldo. Curso de direito do trabalho. 3. ed. Rio de Janeiro: Renovar, 2010. 